\title{
Tax Evasion and Financial Development under Asymmetric Information in Credit Markets*
}

\author{
Jang-Ting Guo ${ }^{\dagger}$ \\ University of California, Riverside \\ Fu-Sheng Hung $\ddagger$ \\ National Chengchi University
}

May 8, 2018

\begin{abstract}
Recent empirical studies have documented that the incidence of firms' tax evasion on their sales is negatively correlated with the country's level of financial development. Our analysis shows that this stylized fact can be theoretically accounted for within a smallopen-economy model of optimal tax enforcement under asymmetric information in credit markets. In an economy with a more developed financial sector that exhibits smaller agency costs, we find that the government will raise its optimal probability of tax auditing, which in turn leads to more tax compliance. It follows that financial development and tax evasion are inversely related, as observed in the actual data.
\end{abstract}

Keywords: Tax Evasion, Financial Development, Asymmetric Information, Credit Rationing.

JEL Classification: D82, H26, H32.

\footnotetext{
${ }^{*}$ We thank seimar participants at National Taiwan University and Feng Chia University for helpful comments and suggestions on an early version of this paper. Part of this research was conducted while Hung was a Fulbright Scholar at University of California, Riverside, whose hospitality is greatly appreciated. Financial support from the Ministry of Science and Technology of R.O.C. is gratefully acknowledged by Hung. Of course, all remaining errors are our own.

${ }^{\dagger}$ Corresponding Author. Department of Economics, 3133 Sproul Hall, University of California, Riverside, CA 92521, USA, Phone: 1-951-827-1588, Fax: 1-951-827-5685, E-mail: guojt@ucr.edu.

${ }^{\ddagger}$ Department of Economics, National Chengchi University, Taipei 116, Taiwan, Phone: 886-2-2938-7369, Fax: 886-2-2939-0344, E-mail: fshung@nccu.edu.tw.
} 


\section{Introduction}

Recent empirical studies have documented that firms in countries with a more developed financial sector would report a larger fraction of their sales to the tax authority. In particular, using a large sample of survey data across 102 countries, Beck et al. (2014) report that firms in countries with a higher ratio of private credit to GDP or a higher degree of financial outreach (i.e. better information-sharing systems and higher bank branch penetration) will evade taxation on their sales to a lesser extent. ${ }^{1}$ Moreover, based on a sample of survey data from 41 countries, Dabla-Norris et al. (2008) find that among firms which regard external financing as a major difficulty, there is a $16 \%$ probability whereby these establishments will hide more than 50 percent of their sales. On the contrary, there is only a $7.6 \%$ probability of firms hiding such a level of sales when they view obtaining external funds as a minor obstacle. These empirical results together illustrate a discernible negative correlation between the incidence of firms' tax evasion on their sales revenue and the economy's financial development that is closely related to the salient feature of asymmetric information in credit markets. ${ }^{2}$ As it turns out, this stylized fact has been left mostly unexplored in existing theoretical studies as tax evasion is mainly attributed to the government's fiscal policy administration through tax rates, the probability of tax detection and its resulting penalty. ${ }^{3}$

Starting from the seminal contribution of Allingham and Sandmo (1972), much effort has been devoted to examining various aspects and effects associated with tax evasion. ${ }^{4}$ In these previous studies, tax evasion is postulated as a risky behavior by rational agents maximizing their expected utility from taxable income. A consensus of this literature is that a more aggressive tax-enforcement policy, through an increase in the auditing probability or the magnitude of fines, will raise the marginal cost of tax evasion and hence leads to more tax compliance (Andreoni et al. [1998] and Sandmo [2005]). ${ }^{5}$ On the other hand, pioneered by the work of Stiglitz and Weiss (1981), it has been shown that asymmetric information in credit markets may give rise to adverse selection and/or moral hazard, thus generating credit rationing in equilibrium.

\footnotetext{
${ }^{1}$ Since King and Levine (1993), the ratio of a country's private credit over GDP has been used as an empirical indicator of financial development

${ }^{2}$ See Levine (1997) for a literature review.

${ }^{3}$ Recent studies by Blackburn et al. (2012) and Capasso and Japplli (2013) have incorporated tax evasion into a model with asymmetric information in credit markets. However, the tax rate is exogenously given and there is no role for government policy of tax enforcement in their analyses. Moreover, these authors focus on firms' tax evasion of the returns from collateral assets, not sales.

${ }^{4}$ See, for example, Andreoni et al. (1998), Alm (1999), Slemrod and Yitzhaki (2002) and Sandmo (2005), among others. Slemrod (2007) provides a literature review on this research topic.

${ }^{5}$ See also survey studies by Spicer and Lundstedt (1976) and Mason and Calvin (1978).
} 
This is detrimental to the economy's aggregate performance as it places considerable strain on firms' investment opportunities. ${ }^{6}$ Since financial development is able to influence the degree of asymmetric information in credit markets, our analysis will investigate its theoretical interrelations with firms' tax evasion on their sales in a simple small-open-economy model under optimal tax enforcement. ${ }^{7}$

In our model economy, each agent/firm is endowed with one unit of time and has access to a risky production opportunity or project. At the beginning of the period, an agent needs to borrow a certain amount of resources from the financial intermediary to obtain state-contingent working capital as an intermediate good for production. As in Bernanke and Gertler (1989), agents are heterogenous since the amount of principal borrowed for each bank loan differs across individual firms. It follows that those establishments who borrow a relatively lower quantity of resources are more efficient agents. After making the loan payment, an agent will combine its remaining productive capital with labor hours to produce output and generate sales revenue. The government imposes a tax rate on firms' reported sales to finance public spending on goods and services that are assumed to be a constant fraction of agents' total output. Moreover, both the true level of working capital and the accurate amount of sales are each firm's private information. As a result, agents may misreport their capital possession to the bank as well as underreport their sales to the fiscal authority. Through the process of backward induction, we first examine agents' optimal decision problem of tax evasion and show that certis paribus an increase in the probability of tax auditing will raise the expected after-tax rate of returns from their production projects as well as the degree of tax complicance by agents. Next, the optimal financial contract that stipulates the bank to audit firms under a bad state for capital acquisition is solved. It turns out that less-efficient establishments will be audited more often by the financial intermediary. Under asymmetric information in the credit market, we analytically derive the equilibrium measure of agents that will obtain working capital and expend labor effort to produce output; and that for inefficient agents who do not receive a bank loan at the outset, thus they will not produce or consume any output.

Finally, a benevolent government is postulated to maximize the economy's social welfare that is defined as agents' aggregate expected net consumption minus the total labor disutility for producing output. Per this optimization problem, we find that a lower agency or monitoring

\footnotetext{
${ }^{6}$ Early examples include Smith and Stutzer (1989), Bencivenga and Smith (1993), and Bose and Cothren (1996, 1997), among others.

${ }^{7}$ With the exceptions of U.S. and China, all countries in the data samples of Dabla-Norris et al. (2008) and Beck et al. (2014) are small open economies.
} 
cost in credit markets will generate an increase in the optimal tax-auditing probability for the government. The intuition for this result is as follows. On the positive side, a reduction in the agency cost is shown to raise firms' expected after-tax rate of returns from their production and tax evasion decisions; hence, agents' aggregate utilities will rise because of their higher consumption spending. On the negative side, a smaller monitoring cost results in more lessefficient firms capable of receiving bank loans, thus the economy's overall production efficiency will fall. In response to these counteracting effects, we show that the government will increase its optimal probability of tax auditing to maintain the maximum for the economy's social welfare function. Since a higher tax-auditing probability leads to more tax compliance, our analysis finds that countries with a more developed financial sector are associated with a less degree of tax evasion on firms' sales. In sum, this paper provides a theoretical explanation for the observed negative correlation between financial development and tax evasion documented by Beck et al. (2014) and Dabla-Norris et al. (2008).

The remainder of this paper is organized as follows. Section 2 presents our small-openeconomy model. Section 3 examines the agent's decision of tax evasion, and then characterizes the government's tax policy administration. Section 4 derives the optimal financial contract between firms and banks under asymmetric information in credit markets. Section 5 studies the optimal policy of tax enforcement and its relationship with financial development. Section 6 concludes.

\section{The Economy}

Consider a small open economy inhabited by a countably infinite number of agents/firms whose population size is normalized to one. As in Bernanke and Gertler (1989), these heterogenous agents are indexed by $\phi$ that is uniformly distributed over the interval $[0,1]$. Each agent is endowed with one unit of time and a risky production opportunity/project. At the beginning of the period, an agent- $\phi$ needs to borrow the principal of $\phi$ units of resources from the financial intermediary to obtain state-contingent working capital as an intermediate good for production. ${ }^{8}$ As a result, low- $\phi$ establishments will incur relatively smaller borrowing as well as production costs, thus they can be regarded as more efficient agents. Banks are competitive and each has access to perfectly-elastic international supply of loanable funds at an exogenous world gross interest rate factor $R_{w}>1$. The amount of productive capital acquired by an individual firm (as a funded agent) takes on two possible values: $\kappa_{1}$ and $\kappa_{2}$, where

\footnotetext{
${ }^{8}$ An agent- $\phi$ who borrows the amount smaller than $\phi$ will not be able to produce any working capital.
} 
the probability that event $\kappa_{i}$ occurs is given by $\pi_{i} \in(0,1)$ with $\pi_{1}+\pi_{2}=1$. It is assumed that $\kappa_{2}>\kappa_{1}>0$, hence $\kappa_{1}\left(\kappa_{2}\right)$ represents the bad(good) state for capital acquisition. After making the loan payment in state $i(=1,2)$, each agent operates a technology that combines its remaining productive capital with $e_{i} \in(0,1)$ units of labor hours to produce output and generate sales revenue. ${ }^{9}$ For the sake of analytical simplicity, we postulate that one unit of capital input will yield one unit of output.

Our model economy exhibits two types of informational imperfection. First, there exists asymmetric information between agents and banks in that the true level of working capital acquired is private information to each firm. Banks can correctly observe the firms' capital ownership only by employing an auditing technology that absorbs $\gamma>0$ units of working capital per producing establishment. As a result, $\gamma$ represents the agency cost between the financial intermediary and firms; and a higher value of $\gamma$ corresponds to a less developed financial sector. It follows that an agent who misreports the bad state of its project, but not being audited by banks, can consume extra output. Second, there exits asymmetric information between producing agents and the government which imposes a tax rate $\tau \in(0,1)$ on firms' reported sales revenue. Since the true amount of output produced is each firm's private information, agents may underreport their sales revenue to tax collectors. Therefore, the government can induce tax compliance by auditing each operational firm with a probability $\eta \in(0,1)$. We also postulate that any under-reporting firm will be audited without error, and that all under-reported sales will be confiscated by the fiscal authority. ${ }^{10}$

The sequence of timing for economic activities proceeds as follows. The tax authority announces the tax rate $\tau$ on firms' sales revenue and the auditing probability $\eta$ at the outset. Taking $\tau$ and $\eta$ as given, each agent decides whether or not to borrow from the financial intermediary. If an agent is unable to borrow, then no output will be produced or consumed. If an agent decides to borrow, s/he must sign a financial contract with the bank to obtain working capital as an intermediate productive input. Each firm reports its capital possession to the bank and makes (principal plus interest) payment on the financial contract; and then combines its remaining working capital with hours worked to operate the production technology. After

\footnotetext{
${ }^{9}$ Since our model economy is static with a single time period, firms will not hold inventory; hence, the amount of output produced by each firm is equal to its sales revenue.

${ }^{10}$ In general, the tax authority can induce tax compliance by selecting the probability of tax auditing and the associated penalty rate. However, Schroyen (1997) points out that the penalty rate is usually stated in a country's law, hence it cannot be directly controlled by the fiscal authority. Moreover, Chen (2003) stipulates that collecting penalties is more efficient than tax auditing since the former is less costly. It follows that it is optimal for the government to set the maximum possible penalty rate, which amounts to confiscating all unreported sales. Under this assumption, our analyses focus on the tax-auditing probability as the only policy instrument for tax compliance.
} 
producing output and generating sales revenue, the firm reports its sales to the government and pays taxes as well as penalties when audited. Subsequently, an agent consumes the residual output with a linear utility function given by

$$
U=c-e,
$$

where $c$ denotes the net consumption after taxes/penalties and loan payments are made, and $e$ represents labor disutility from the production of output. Notice that $c=e=0$ when an agent decides not to borrow or $\mathrm{s} /$ he is credit rationed without obtaining bank loans.

In what follows via the process of backward induction, we first analyze the agent's decision on tax evasion, while taking the government's tax rate $\tau$ and tax-auditing probability $\eta$ as given. This will determine the expected after-tax rate of returns from production. Next, we derive the optimal financial contract between firms and banks that maximizes the agent's expected utility under a competitive financial system. Finally, we examine the government's optimal policy of tax enforcement and its interrelations with the degree of financial development represented by $\gamma$.

\section{Optimal Tax Evasion}

Suppose that an agent- $\phi$, after obtaining working capital from the bank and expending its labor hours, produces $y>0$ units of (before-tax) output/sales. Since the production outcome is private information, the firm may evade taxes by only reporting a $\beta \in(0,1)$ fraction of its sales to the government. Therefore, the firm derives $\beta(1-\tau) y$ units of after-tax output, and retains $(1-\beta) y$ units of sales without being audited by the tax authority. As in Chen (2003), we postulate that the transaction costs to a tax-evading firm is equal to $\frac{(1-\beta)^{2}}{2} y$. Since the tax authority audits each firm with probability $\eta$ and all unreported output will be confiscated under tax detection, the expected after-tax output/sales $y^{\text {after-tax }}$ is given by

$$
y^{a f t e r-t a x}=\beta(1-\tau) y+(1-\beta)(1-\eta) y-\frac{(1-\beta)^{2}}{2} y .
$$

Taking $\tau$ and $\eta$ as given, the first-order condition from firms' maximizing $y^{\text {after-tax }}$ leads to the following optimal fraction of sales reported to the tax authority:

$$
\beta^{*}=1-\tau+\eta
$$


where $\tau>\eta$ is assumed to ensure that $0<\beta^{*}<1$. Plugging (3) into (2) shows that the expected after-tax rate of returns from the firm's output production and tax evasion decisions $\left(=\frac{y^{a f t e r-t a x}}{y}\right)$ is

$$
r^{*}=\beta^{*}(1-\tau)+\left(1-\beta^{*}\right)(1-\eta)-\frac{\left(1-\beta^{*}\right)^{2}}{2},
$$

where $0<r^{*}<1$. Notice that equations (3) and (4) indicate that the firm's decision of tax evasion is affected by the tax rate $\tau$ and the probability of tax detection $\eta$.

Next, the government is postulated to finance an exogenously-given level of public expenditures $g>0$ that are set to be a constant proportion $\theta \in(0,1)$ of the firm's sales $y$. As each firm reports a fraction $\beta^{*}$ of its output, the government's tax revenue is $\beta^{*} \tau y$. In addition, the unreported sales $\left(1-\beta^{*}\right) y$ will be confiscated by the tax authority under the auditing probability $\eta$. It follows that the balanced government budget is governed by

$$
\theta=\beta^{*} \tau+\left(1-\beta^{*}\right) \eta
$$

Proposition 1. For a given probability of tax auditing $\eta$, there may exist two tax rates (denoted as $\tau_{1}^{*}$ and $\tau_{2}^{*}$ ) that satisfy the balanced government budget (5).

Using equations (3) and (5), it is straightforward to obtain Figure 1 which depicts a Laffer curve-type relationship between $\theta$ and $\tau$, while taking the tax-detection probability $\eta$ as given. Setting $\frac{\partial \theta}{\partial \tau}=0$ yields that there exists a unique tax rate $\hat{\tau} \in(0,1)$ which maximizes the government's revenue (including penalties) as a friction of total output/sales denoted by $\hat{\theta}$. It follows that an increase in the tax rate $\tau$ will generate two opposite effects. On the one hand, equation (5) shows that it directly raises the ratio of public spending to total output/sales. On the other hand, equation (3) shows that it produces less tax compliance $\left(\frac{\partial \beta^{*}}{\partial \tau}<0\right)$, which in turn decreases the value of $\theta$. Figure 1 illustrates that since the first (second) effect dominates when $\tau>(<) \hat{\tau}$, an inverted-U curve ensues. As a result, our model possesses zero (two) interior equilibrium tax rates provided $\theta>(<) \hat{\theta}$. After substituting $\beta^{*}$ from (3) into (5), we find that when $\theta \in(0, \hat{\theta})$ as shown in Figure 1 , the analytical expressions for $\tau_{1}^{*}$ and $\tau_{2}^{*}$ (as functions of $\eta$ ) are

$$
\tau_{1}^{*}(\eta)=\frac{1+2 \eta-\sqrt{1-4(\theta-\eta)}}{2}
$$

and

$$
\tau_{2}^{*}(\eta)=\frac{1+2 \eta+\sqrt{1-4(\theta-\eta)}}{2}
$$




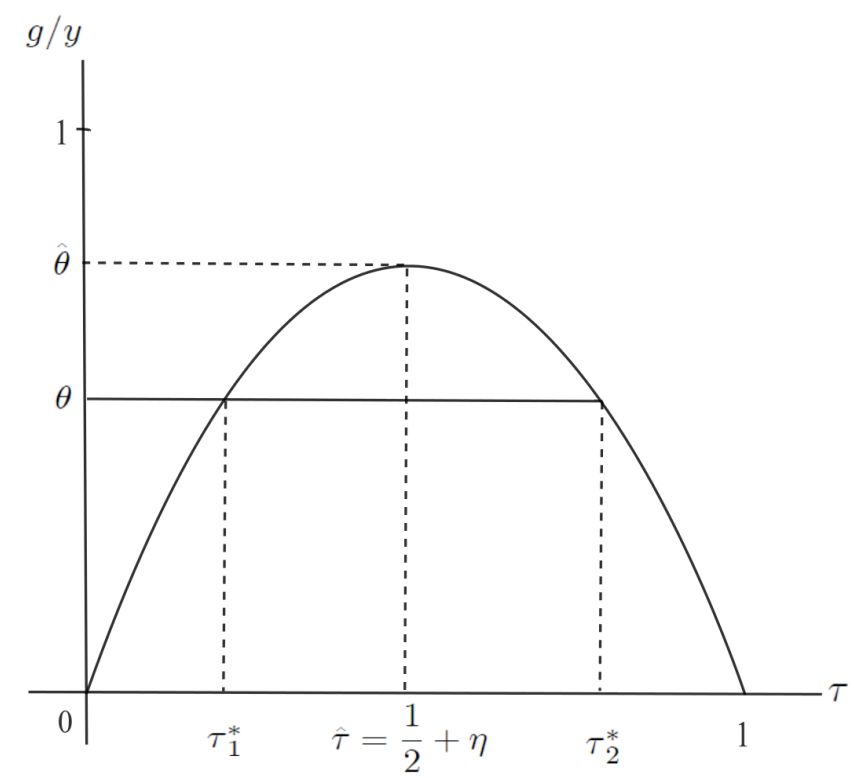

Figure 1: Equilibrium Laffer-Curve Relationship between $\theta$ and $\tau$

where $1-4(\theta-\eta)>0$ and $0<\tau_{1}^{*}(\eta)<\hat{\tau}=\frac{1}{2}+\eta<\tau_{2}^{*}(\eta)<1$.

Substituting $\tau_{1}^{*}(\eta)$ and $\tau_{2}^{*}(\eta)$ into (3) derives that the corresponding expressions for firms' optimal fractions of output/sales reported to the tax authority are

$$
\beta_{1}^{*}(\eta)=\frac{1+\sqrt{1-4(\theta-\eta)}}{2}
$$

and

$$
\beta_{2}^{*}(\eta)=\frac{1-\sqrt{1-4(\theta-\eta)}}{2}
$$

where $0<\beta_{2}^{*}(\eta)<\beta_{1}^{*}(\eta)<1$. In addition, we note that $\frac{\partial \beta_{1}^{*}(\eta)}{\partial \eta}>0$ and $\frac{\partial \beta_{2}^{*}(\eta)}{\partial \eta}<0$. Based on the pioneer work of Allingham and Sandmo (1972) and numerous subsequent theoretical studies, it is generally accepted that a more aggressive tax-detection policy, such as an increase in the probability of tax auditing $\eta$, is able to mitigate the incidence of tax evasion. On the empirical front, Sheffrin and Triest (1992) examine a cross sectional sample of survey data, and find that taxpayers who perceive a higher audit probability will report significantly less understating of their income. ${ }^{11}$ However, the result that $\frac{\partial \beta_{2}^{*}(\eta)}{\partial \eta}<0$ contradicts this consensus.

\footnotetext{
${ }^{11}$ In general, since data related to the tax auditing probability is not readily available, it is not straightforward to directly test the relationhsip between the audit probability and tax evasion. Spicer and Thomas (1982) adopt an experimental approach to show that an increase in the tax auditing probability leads to a decrease in the degree of tax evasion. Similarly, Slemrod, Blumenthalb, and Christian (2001) analyze a controlled experiment
} 
To maintain consistency with the existing literature, we will rule out $\tau_{2}^{*}(\eta)$ and $\beta_{2}^{*}(\eta)$ in the ensuing analyses; and focus on the case with $\tau^{*}(\eta) \equiv \tau_{1}^{*}(\eta)$ and $\beta^{*}(\eta) \equiv \beta_{1}^{*}(\eta)$ from now on.

From equation $(6)$ with $\sqrt{1-4(\theta-\eta)} \in(0,1)$, it is straightforward to show that

$$
\frac{\partial \tau^{*}(\eta)}{\partial \eta}=1-\frac{1}{\sqrt{1-4(\theta-\eta)}}<0
$$

Since a higher tax-auditing probability induces more tax compliance $\left(\frac{\partial \beta^{*}(\eta)}{\partial \eta}>0\right.$ per equation 8$)$, the government's balanced budget as in (5) can be maintained with a lower tax rate $\tau^{*}(\eta)$. Substituting equations (6) and (8) into (4), we obtain the following expression for the expected after-tax rate of returns as a function of $\eta$ :

$r^{*}(\eta)=\frac{(1-\eta)[1-\sqrt{1-4(\theta-\eta)}]}{2}+\frac{[1+\sqrt{1-4(\theta-\eta)}][1-2 \eta+\sqrt{1-4(\theta-\eta)}]}{4}-\frac{[1-\sqrt{1-4(\theta-\eta)}]^{2}}{8}$

and then find that

$$
\frac{\partial r^{*}(\eta)}{\partial \eta}=\frac{1-\sqrt{1-4(\theta-\eta)}}{2 \sqrt{1-4(\theta-\eta)}}>0
$$

hence an increase in the probability of tax auditing will raise the expected after-tax rate of returns from firms' production and tax evasion decisions.

\section{Optimal Financial Contract}

This section derives the optimal financial contract between financial intermediaries and heterogenous firms. In particular, an agent- $\phi$ needs to first borrow the principal of $\phi$ units of resources to obtain state-contingent working capital, which takes on the value of $\kappa_{1}\left(\kappa_{2}\right)$ in the bad(good) state, as an intermediate good for production. On the other hand, a competitive bank offers the contract that maximizes agent- $\phi$ 's expected utility, taking into account the world interest factor $R_{w}$, as well as the fact that the true outcome of firms' capital acquisition is private information. When the bad state (state 1) takes place, the bank audits a firm with probability $p \in[0,1]$ and agency/monitoring $\operatorname{cost} \gamma$; and then receives the total payment (principal plus interest) of $T^{a}$. We also denote $T_{1}$ and $T_{2}$ as the total payment that an unaudited firm will pay to the bank under the bad and good states, respectively. After making the

on a group of randomly selected Minnesota taxpayers who were informed in 1995 that the tax returns they were about to file would be "closely examined". These authors find that low- and middle-income taxpayers, on average, have raised their tax payments compared to those in the previous year. 
loan payment, an agent combines its remaining productive capital with $e_{1}\left(e_{2}\right) \in(0,1)$ units of labor hours to produce output and collect sales revenue in the bad(good) state. ${ }^{12}$ For the sake of analytical simplicity, we postulate that one unit of working capital will generate one unit of output.

With the expected after-tax rate of returns from firms' production and tax evasion decisions $r^{*}(\eta) \grave{a} l a(11)$ taken as given, the optimal financial contract is obtained by choosing the bank-auditing probability $p$ together with the repayment schedule $\left\{T^{a}, T_{1}, T_{2}\right\}$ to maximize agent- $\phi$ 's expected utility given by

$$
\pi_{1}\{\underbrace{r^{*}(\eta)\left[\kappa_{1}-p T^{a}-(1-p) T_{1}\right]}_{=y_{1}^{\text {after }- \text { tax }}}-e_{1}\}+\pi_{2}\{\underbrace{r^{*}(\eta)\left(\kappa_{2}-T_{2}\right)}_{=y_{2}^{\text {after-tax }}}-e_{2}\}
$$

subject to

$$
\begin{gathered}
\pi_{1}\left[p T^{a}+(1-p) T_{1}-p \gamma\right]+\pi_{2} T_{2} \geq \phi R_{w}, \\
r^{*}(\eta)\left(\kappa_{2}-T_{2}\right)-e_{2} \geq(1-p)\left[r^{*}(\eta)\left(\kappa_{1}-T_{1}\right)+r^{*}(\eta)\left(\kappa_{2}-\kappa_{1}\right)\right]-e_{2}, \\
r^{*}(\eta)\left(\kappa_{1}-T^{a}\right)-e_{1} \geq 0 \\
r^{*}(\eta)\left(\kappa_{1}-T_{1}\right)-e_{1} \geq 0 \\
\pi_{1}\left\{r^{*}(\eta)\left[\kappa_{1}-p T^{a}-(1-p) T_{1}\right]-e_{1}\right\}+\pi_{2}\left\{r^{*}(\eta)\left(\kappa_{2}-T_{2}\right)-e_{2}\right\} \geq 0,
\end{gathered}
$$

where $\left[\kappa_{1}-p T^{a}-(1-p) T_{1}\right]$ and $y_{1}^{a f t e r-t a x}$ are the agent's expected post-loan-payment working capital and after-tax output/consumption in the bad state; whereas $\left(\kappa_{2}-T_{2}\right)$ and $y_{2}^{a f t e r-t a x}$ represent the corresponding variables in the good state. Equation (14) states that the expected net revenue (including the agency cost $\gamma$ ) undertaken by a bank is not lower than its total cost of securing funds from the international financial market at the world interest factor $R_{w}$. Moreover, equation (15) is the incentive-compatibility (or truth-telling) constraint which prevents agents under the good state from misreporting the bad state to a financial intermediary. ${ }^{13}$ Equations (16)-(17) require that the agent's realized utility must be nonnegative in the bad state, regardless of whether it is audited by the bank or not. ${ }^{14}$ Finally, equation (18)

\footnotetext{
${ }^{12}$ We do not need to postulate the relationship between $e_{1}$ and $e_{2}$, i.e. whether $e_{1} \lesseqgtr e_{2}$, since it does not affect any of our results below.

${ }^{13}$ Notice that $r^{*}(\eta)\left(\kappa_{2}-\kappa_{1}\right)$ is the difference of after-tax output/sales between the good and bad states. With probability $1-p$, an unaudited agent who is in the good state but misreports the bad state can enjoy $r^{*}(\eta)\left(\kappa_{1}-T_{1}\right)$ as well as the extra amount of $r^{*}(\eta)\left(\kappa_{2}-\kappa_{1}\right)$ for consumption.

${ }^{14}$ As in Bernanke and Gertler (1989), these two inequalities are the "limited liability" constraints.
} 
is the participation constraint on the agents' expected utility across the two states (13) to be nonnegative.

Proposition 2. For a given probability of tax auditing $\eta$, the optimal contract that a competitive bank offers to agent- $\phi$ is characterized by

$$
\begin{gathered}
T^{a}=T_{1}=\kappa_{1}, \\
T_{2}=\kappa_{2}-(1-p)\left(\kappa_{2}-\kappa_{1}\right), \quad \text { and } \\
p=\frac{\phi R_{w}-\kappa_{1}}{\pi_{2}\left(\kappa_{2}-\kappa_{1}\right)-\pi_{1} \gamma} .
\end{gathered}
$$

Based on the revelation principle, setting the agent's utility level to zero in either scenario of the bad state (being audited or not) will eliminate its incentive for misreporting. Hence, equations (16) and (17) will be binding with $T^{a}=T_{1}=\kappa_{1}-\frac{e_{1}}{r^{*}(\eta)}$. It follows that there are two possible outcomes after the firm makes its loan payment in the bad state: (i) the remaining working capital $\left[\kappa_{1}-p T^{a}-(1-p) T_{1}\right]$ is positive, thus an agent will expend labor hours to produce output with $y_{1}^{a f t e r-t a x}=e_{1}>0$; and (ii) the agent does not retain any working capital under $T^{a}=T_{1}=\kappa_{1}$, thus no labor effort is expended and no output will be produced $\left(y_{1}^{a f t e r-t a x}=e_{1}=0\right)$. In the Appendix $A$, we show that the agent's utility is higher under (ii), hence the financial intermediary will take away all working capital from firms when the bad state takes place. As a consequence, the extra consumption that an unaudited firm can enjoy from misreporting the good state, as in the first term from the right-hand-side of (15), is equal to $(1-p) r^{*}(\eta)\left(\kappa_{2}-\kappa_{1}\right)$. It follows that the binding incentive-compatibility constraint (15) results in $T_{2}=\kappa_{2}-(1-p)\left(\kappa_{2}-\kappa_{1}\right)$. Substituting these expressions for $T^{a}, T_{1}$ and $T_{2}$ into equation (14) with equality (i.e. the zero-profit condition) yields that the competitive bank's optimal auditing probability $p$ is given by (21). This in turn implies that certis paribus less-efficient agents, who (if funded) borrow a relatively higher amount of resources, will be audited more often by the bank $\left(\frac{\partial p}{\partial \phi}>0\right)$.

In terms of the range of $\phi$ over which firms will receive loans from financial intermediaries, we first set $p=0$ and find that

$$
\underline{\phi}=\frac{\kappa_{1}}{R_{w}}
$$


For those agents with $\phi<\phi$, their production efficiency is so high that they always report the true outcome of capital acquisition to the bank, and they are able to pay back the loan's full amount even in the bad state. Therefore, these firms will not be audited by the bank and there is no agency problem associated with them. Next, we set $p=1$ and find that

$$
\bar{\phi}=\frac{\kappa_{1}+\pi_{2}\left(\kappa_{2}-\kappa_{1}\right)-\pi_{1} \gamma}{R_{w}} .
$$

For those agents with $\phi>\bar{\phi}$, their production efficiency is so low that they are unable to make the loan payment even in the good state.

Moreover, substituting the optimal financial contract (19)-(21) into equation (18) yields that the critical level of $\phi$ which will bind the agent's participation constraint is given by

$$
\phi^{c}(\eta)=\frac{\kappa_{1}+\left[1-\frac{e_{2}}{r^{*}(\eta)\left(\kappa_{2}-\kappa_{1}\right)}\right]\left[\pi_{2}\left(\kappa_{2}-\kappa_{1}\right)-\pi_{1} \gamma\right]}{R_{w}},
$$

where $\frac{e_{2}}{r^{*}(\eta)\left(\kappa_{2}-\kappa_{1}\right)} \in(0,1) .{ }^{15}$ For those inefficient agents with $\phi>\phi^{c}(\eta)$ and negative expected utility, they will choose not to participate in the credit market at the outset, and do not produce or consume any output.

Since $0<\underline{\phi}<\phi^{c}(\eta)<\bar{\phi}<1,{ }^{16}$ we have shown that agents with $\phi<\underline{\phi}$ will borrow from the financial intermediary without any informational imperfection; that the economy's aggregate amount of lending/borrowing with costly monitoring is equal to $\phi^{c}(\eta)-\underline{\phi}$; and that agents with $\phi>\phi^{c}(\eta)$ will not receive bank loans.

\section{Optimal Tax Enforcement}

In this section, we first consider a benevolent government that chooses the optimal probability of tax auditing $\eta^{*}$ to maximize the economy's social welfare $S W$, which is defined as the aggregate expected utilities across all agents:

$$
S W=\int_{0}^{1} \pi_{1}\left\{r^{*}(\eta)\left[\kappa_{1}-p T^{a}-(1-p) T_{1}\right]-e_{1}\right\}+\pi_{2}\left\{r^{*}(\eta)\left(\kappa_{2}-T_{2}\right)-e_{2}\right\} h(\phi) d \phi,
$$

where the vector $\left\{T^{a}, T_{1}, T_{2}, p\right\}$ is taken from equations (19)-(21) that characterize the optimal financial contract, and $h(\phi)=1$ is the probability density of an uniform distribution over the

\footnotetext{
${ }^{15}$ Under the optimal financial contract with $T^{a}=T_{1}=\kappa_{1}$, the expected utility (13) is equal to $\pi_{2}(1-p) r^{*}(\eta)\left(\kappa_{2}-\kappa_{1}\right)-e_{2}$. If $e_{2}>r^{*}(\eta)\left(\kappa_{2}-\kappa_{1}\right)$, then agents' expected utility will become negative in that $0<\pi_{2}<1$ and $0 \leq p \leq 1$. As a result, the restriction of $\frac{e_{2}}{r^{*}(\eta)\left(\kappa_{2}-\kappa_{1}\right)} \in(0,1)$ is imposed.

${ }^{16}$ Since the bank's auditing probability $p \in[0,1]$, the denominator in equation (21), given by $\pi_{2}\left(\kappa_{2}-\kappa_{1}\right)-\pi_{1} \gamma$, is positive. This, together with $0<\frac{e_{2}}{r^{*}(\eta)\left(\kappa_{2}-\kappa_{1}\right)}<1$, implies that $0<\underline{\phi}<\phi^{c}(\eta)<\bar{\phi}<1$.
} 
interval $[0,1]$. Based on the analysis from the previous section, agents/firms in our model can be divided into the following three subgroups:

(i) Agents with $\phi \in[0, \underline{\phi}$, where $\underline{\phi}$ is given by (22) - these firms are sufficiently efficient without default risk, thus the bank will not audit them in the bad state. Substituting (19), (20), (22) and $p=0$ into (25) yields that the aggregate welfare for this subgroup is

$$
S W_{1}=\int_{0}^{\underline{\phi}}\left[\pi_{2} r^{*}(\eta)\left(\kappa_{2}-\kappa_{1}\right)\right] h(\phi) d \phi-e_{2} \int_{0}^{\underline{\phi}} h(\phi) d \phi .
$$

(ii) Agents with $\phi \in\left[\phi, \phi^{c}(\eta)\right]$, where $\phi^{c}(\eta)$ is given by $(24)$ - these firms will receive bank loans under asymmetric information in credit markets, subject to the bank-auditing probability $p \in(0,1)$ as in $(21)$. It is straightforward to show that the aggregate welfare for this subgroup is

$$
S W_{2}=\int_{\underline{\phi}}^{\phi^{c}(\eta)}\left[\pi_{2}(1-p) r^{*}(\eta)\left(\kappa_{2}-\kappa_{1}\right)\right] h(\phi) d \phi-e_{2} \int_{\underline{\phi}}^{\phi^{c}(\eta)} h(\phi) d \phi .
$$

(iii) Agents with $\phi \in\left[\phi^{c}(\eta), 1\right]$ - these inefficient agents do not receive bank loans, hence they will not engage in production or consume any output. It follows that the aggregate welfare for this subgroup is $S W_{3}=0$.

In the Appendix $B$, we use (26) and (27) to obtain the first-order condition for the government's optimization problem with respect to its tax-auditing probability $\left(\frac{\partial S W}{\partial \eta}=0\right)$; and then find that the expected after-tax rate of returns from firms' production and tax evasion decisions will be a constant, denoted as $M \in(0,1)$, in equilibrium: ${ }^{17}$

$$
r^{*}=\frac{e_{2}}{\kappa_{2}-\kappa_{1}} \sqrt{\frac{\pi_{2}\left(\kappa_{2}-\kappa_{1}\right)-\pi_{1} \gamma}{2 \kappa_{1}+\pi_{2}\left(\kappa_{2}-\kappa_{1}\right)-\pi_{1} \gamma}} \equiv M
$$

Proposition 3. There exists a unique optimal probability of tax auditing $\eta^{*} \in(0,1)$ in our model economy.

Using equations (11) and (12), it is straightforward to show that

$$
\frac{\partial^{2} r^{*}(\eta)}{\partial \eta^{2}}=\frac{-1}{[1-4(\theta-\eta)]^{\frac{3}{2}}}<0
$$

This finding, together with $\frac{\partial r^{*}(\eta)}{\partial \eta}>0$, implies that $r^{*}(\eta)$ is an upward-sloping curve which is

\footnotetext{
${ }^{17}$ Recall that $r^{*}$ is equal to the ratio of firms' after-tax to befor-tax output $\left(=\frac{y^{a f t e r-t a x}}{y}\right)$, hence it is a positive number which is smaller than one.
} 


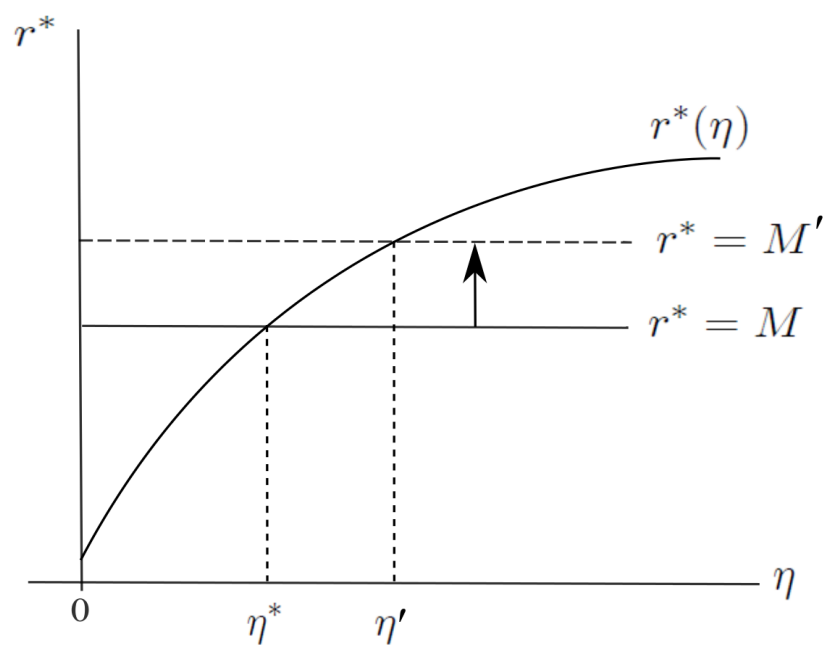

Figure 2: Optimal Tax-Auditing Probability $\eta^{*}$ when $\gamma$ Falls

concave to the origin, as shown in Figure 2. ${ }^{18}$ On the other hand, Figure 2 also illustrates that the equilibrium condition (28) is depicted as a horizontal line. It follows that their intersection will yield our model's unique optimal tax-auditing probability $\eta^{*}$, and that the corresponding optimal $\tau^{*}$ and $\beta^{*}$ can then be derived through equations (6) and (8).

We then take total differentiation on the equality between (11) and (28) to obtain

$$
\frac{d \eta^{*}}{d \gamma}=-\underbrace{\frac{1}{\partial r^{*}(\eta)}}_{\text {positive }} \frac{\pi_{1} \kappa_{1} e_{2}}{\left(\kappa_{2}-\kappa_{1}\right) \sqrt{\pi_{2}\left(\kappa_{2}-\kappa_{1}\right)-\pi_{1} \gamma}\left[2 \kappa_{1}+\pi_{2}\left(\kappa_{2}-\kappa_{1}\right)-\pi_{1} \gamma\right]^{\frac{3}{2}}}<0
$$

which indicates that the government in countries with a more developed financial sector, represented by a smaller agency $\operatorname{cost} \gamma$, will adopt a higher tax-detection probability $\eta^{*}$. Next, using the chain rule leads to the relationship between firms' optimal fraction of sales reported to the tax authority (or tax compliance) and financial development:

$$
\frac{d \beta^{*}}{d \gamma}=\underbrace{\frac{d \beta^{*}}{d \eta^{*}}}_{\text {positive negative }} \underbrace{\frac{d \gamma}{2}}_{\frac{d \eta^{*}}{d \gamma}}<0
$$

where $\frac{d \beta^{*}}{d \eta^{*}}$ can easily be derived from equation (8) evaluated at the optimal probability of tax auditing $\eta^{*}$. It follows that

\footnotetext{
${ }^{18}$ Plugging $\eta=0$ into equation (11) shows that the intercept on the vertical axis of Figure 2 is $r^{*}=$ $\frac{1+2(1-\theta)+\sqrt{1-4 \theta}}{4}>0$.
} 
Proposition 4. Financial development, measured by a lower level of the agency cost $\gamma$, leads to a decrease in the incidence of tax evasion.

This is our main finding. Since the optimal fraction of firms' unreported sales is given by $\left(1-\beta^{*}\right)$ in our model, the preceding (31) implies that financial development and tax evasion are inversely related, as observed in the actual data documented by Beck et al. (2014) and Dabla-Norris et al. (2008). The intuition for this result is as follows. Using equation (28), it is straightforward to show that with a more developed financial sector, a reduction in the agency cost shifts up the horizontal line in Figure 2 and thus raises the equilibrium expected after-tax rate of returns from firms' production and tax evasion decisions to $r^{*}=M^{\prime}>M$. It follows agents' aggregate utilities will rise because of their higher consumption spending (see equations 26 and 27). On the other hand, a smaller $\gamma$ also induces more less-efficient firms to receive bank loans, which generates an increase in the total amount of lending/borrowing under costly monitoring given by $\phi^{c}(\eta)-\underline{\phi}$ (see equation 24 with $\left.\frac{\partial \phi^{c}(\eta)}{\partial \gamma}<0\right)$. It follows that the economy's overall production efficiency will become lower. In response to these counteracting effects, Figure 2 together with (30) show that the government will increase its optimal probability of tax auditing $\left(\eta^{\prime}>\eta^{*}\right)$ to maintain the maximum of the social welfare function (25). Since

a higher tax-auditing probability yields more tax compliance, i.e. $\frac{d \beta^{*}}{d \eta^{*}}>0$ à la (8), an empirically-realistic negative correlation between the level of financial development and firms' tax evasion ensues. As a result, it is socially optimal for the government in countries with a less developed financial sector to implement a relatively looser policy of tax enforcement, which in turn will lead to a higher degree of tax evasion.

\section{Conclusion}

In this paper, we integrate asymmetric information in credit markets with the government's optimal policy of tax enforcement to examine the theoretical interrelations between financial development and tax evasion within a small open economy. Heterogenous agents/firms seek to obtain state-contingent working capital from competitive banks for producing output, and the government imposes a tax rate on firms' total reported sales. Both the true outcome of production and the accurate amount of sales are each firm's private information. Therefore, agents may misreport their capital possession to the bank as well as underreport their sales to the fiscal authority. We first analyze the firm's optimal decisions on output production and tax evasion, and find that raising the government's tax-detection probability leads to more tax compliance by agents. Next, we analytically derive the optimal financial contract 
that determines the equilibrium measure of firms that will receive bank loans and produce output. Finally, we solve the optimization problem for a benevolent government, and show that a lower agency cost in credit markets will generate an increase in the socially optimal taxauditing probability. These findings altogether imply that countries with a more developed financial sector are associated with a less degree of tax evasion on firms' sales. In sum, our analysis provides a theoretical explanation for the observed negative correlation between financial development and tax evasion documented by recent empirical studies.

This paper can be extended in several directions. For example, Beck et al. (2014) report that the degree of tax evasion is lower in countries with a better information sharing system. To shed light on this stylized fact, it would be worthwhile to analyze how information sharing (e.g. Pagano and Jappelli [1993] and Padilla and Pagano [2000]) may affect firms' decision to evade taxation. In addition, while agents in our model are heterogeneous with respect to the amount of their borrowing, the size of production (measured by the quantity of working capital or sales) is identical across all firms. However, Beck et al. (2014) find that the observed negative correlation between financial development and tax evasion is stronger for smaller firms. Incorporating the heterogeneity of firms' size into our model will thus allow us to examine the robustness of this paper's theoretical results and policy implications. We plan to pursue these research projects in the near future. 


\section{Appendix A}

Based on the revelation principle, an agent's expected utility will be equal to zero in the bad state, regardless of whether it is audited by the bank or not. In this Appendix, we will compare the agent's utility in the good state, which is given by $(1-p) r^{*}(\eta)\left[\left(\kappa_{1}-T_{1}\right)+\left(\kappa_{2}-\kappa_{1}\right)\right]-e_{2}$ from the binding incentive-compatibility constraint (15), under (i) $T^{a}=T_{1}=\kappa_{1}-\frac{e_{1}}{r^{*}(\eta)}$, where $e_{1}>0$ versus that under (ii) $T^{a}=T_{1}=\kappa_{1}$ and $e_{1}=0$. In the fomer case (i), the total loan payment made by a funded firm and the resulting optimal bank-auditing probability are

$$
\begin{gathered}
T_{2}\left(e_{1}>0\right)=\kappa_{2}-(1-p)\left[\kappa_{2}-\kappa_{1}+\frac{e_{1}}{r^{*}(\eta)}\right], \text { and } \\
p\left(e_{1}>0\right)=\frac{\phi R_{w}-\kappa_{1}+\frac{e_{1}}{r^{*}(\eta)}}{\pi_{2}\left(\kappa_{2}-\kappa_{1}\right)-\pi_{1} \gamma+\frac{e_{1}}{r^{*}(\eta)}} .
\end{gathered}
$$

It follows that the agent's utility in the good state is given by

$$
U\left(e_{1}>0\right)=\frac{\left[r^{*}(\eta)\left(\kappa_{2}-\kappa_{1}\right)+e_{1}\right]\left\{\pi_{1} \kappa_{1}+\pi_{2} \kappa_{2}-\phi R_{w}-\pi_{1}\left[\gamma+\frac{e_{1}}{r^{*}(\eta)}\right]\right\}}{\pi_{2}\left(\kappa_{2}-\kappa_{1}\right)-\pi_{1} \gamma+\frac{e_{1}}{r^{*}(\eta)}}-e_{2} .
$$

In the latter case (ii), it is straightforward to derive that the corresponding utility in the good state is

$$
U\left(e_{1}=0\right)=\frac{r^{*}(\eta)\left(\kappa_{2}-\kappa_{1}\right)\left[\pi_{1}\left(\kappa_{1}-\gamma\right)+\pi_{2} \kappa_{2}-\phi R_{w}\right]}{\pi_{2}\left(\kappa_{2}-\kappa_{1}\right)-\pi_{1} \gamma}-e_{2} .
$$

Taking the difference between (A.4) and (A.3) shows that $U\left(e_{1}=0\right)-U\left(e_{1}>0\right)$

$$
=\frac{\pi_{1} \gamma\left[\pi_{1}\left(\kappa_{1}-\gamma\right)+\pi_{2} \kappa_{2}-\phi R_{w}\right]}{\left[\pi_{2}\left(\kappa_{2}-\kappa_{1}\right)-\pi_{1} \gamma\right]\left[\pi_{2}\left(\kappa_{2}-\kappa_{1}\right)-\pi_{1} \gamma+\frac{\pi_{2} e_{1}}{r^{*}(\eta)}\right]}+\frac{\pi_{1} e_{1}\left[r^{*}(\eta)\left(\kappa_{2}-\kappa_{1}\right)+e_{1}\right]}{r^{*}(\eta)\left[\pi_{2}\left(\kappa_{2}-\kappa_{1}\right)-\pi_{1} \gamma+\frac{\pi_{2} e_{1}}{r^{*}(\eta)}\right]}>0
$$

As a result, the optimal financial contract between banks and firms will be characterized by $T^{a}=T_{1}=\kappa_{1}$ and $e_{1}=0$, i.e. agents' working capital is completely taken away and thus no output is produced in the bad state.

\section{Appendix B}

Using equation (26) for the aggregate welfare of subgroup (i), it is straightforward to show that 


$$
\frac{\partial S W_{1}}{\partial \eta}=\frac{\partial r^{*}(\eta)}{\partial \eta}\left\{\frac{\pi_{2} \kappa_{1}\left(\kappa_{2}-\kappa_{1}\right)}{R_{w}}\right\}
$$

where $\frac{\partial r^{*}(\eta)}{\partial \eta}>0$ is given by (12). Similarly, we use equation (27) for the aggregate welfare of subgroup (ii) to derive that

$$
\frac{\partial S W_{2}}{\partial \eta}=\frac{\partial r^{*}(\eta)}{\partial \eta}\left\{\frac{\pi_{2}\left(\kappa_{2}-\kappa_{1}\right)\left[\pi_{2}\left(\kappa_{2}-\kappa_{1}\right)-\pi_{1} \gamma\right]}{2 R_{w}}\right\}\left\{1-\left[\frac{e_{2}}{r^{*}(\eta)\left(\kappa_{2}-\kappa_{1}\right)}\right]^{2}\right\} .
$$

Since the aggregate welfare of subgroup (iii) is zero $\left(S W_{3}=0\right), \frac{\partial S W}{\partial \eta}=\frac{\partial S W_{1}}{\partial \eta}+\frac{\partial S W_{2}}{\partial \eta}$. After taking the summation of (B.1) and (B.2), we find that

$$
\frac{\partial S W}{\partial \eta}=\underbrace{\frac{\partial r^{*}(\eta)}{\partial \eta}}_{\text {positive }}\left\{\frac{\pi_{2}\left(\kappa_{2}-\kappa_{1}\right)\left[2 \kappa_{1}+\pi_{2}\left(\kappa_{2}-\kappa_{1}\right)-\pi_{1} \gamma\right]}{2 R_{w}}\right\}\left\{1-\left[\frac{e_{2}}{r^{*}(\eta)\left(\kappa_{2}-\kappa_{1}\right)}\right]^{2}\right\}
$$

Finally, setting $\frac{\partial S W}{\partial \eta}=0$ yields the following quadratic equation in $r^{*}(\eta)$ :

$$
\left\{\left[2 \kappa_{1}+\pi_{2}\left(\kappa_{2}-\kappa_{1}\right)-\pi_{1} \gamma\right]\left(\kappa_{2}-\kappa_{1}\right)^{2}\right\}\left[r^{*}(\eta)\right]^{2}=\left[\pi_{2}\left(\kappa_{2}-\kappa_{1}\right)-\pi_{1} \gamma\right] e_{2}^{2} .
$$

The positive solution to (B.4) results in equation (28) in the main text. 


\section{References}

[1] Alm, J. (1999), "Tax Compliance and Administration," Public Administration and Public Policy $72,741-768$.

[2] Allingham, M.G. and A. Sandmo (1972),."Income Tax Evasion: A Theoretical Analysis," Journal of Public Economics 1, 323-338.

[3] Andreoni, J., B. Erard, and J. Feinstein (1998), "Tax Compliance," Journal of Economic Literature 36, 818-860.

[4] Bencivenga, V.R. and B.D. Smith (1993), "Some Consequences of Credit Rationing in an Endogenous Growth Model," Journal of Economic Dynamics and Control 17, 97-122.

[5] Beck, T., A.L. Chen, and A.U. Yue (2014), "Why Do Firms Evade Taxes? The Role of Information Sharing and Financial Sector Outreach," Journal of Finance 69, 763-817.

[6] Bernanke, B. and M. Gertler (1989), "Agency Costs, Net Worth, and Business Fluctuations," American Economic Review 79, 14-31.

[7] Blackburn, K., N. Bose, and S. Capassom (2012), "Tax Evasion, the Underground Economy, and Financial Development," Journal of Economic Behavior and Organization 83, 243-253.

[8] Bose, N. and R. Cothren (1996), "Equilibrium Loan Contracts and Endogenous Growth in the Presence of Asymmetric Information," Journal of Monetary Economics 38, 363-376.

[9] Bose, N. and R. Cothren (1997), "Asymmetric Information and Loan Contracts in a Neoclassical Growth Model," Journal of Money, Credit, and Banking 29, 423-439.

[10] Capasso, S. and T. Jappelli (2013), "Financial Development and the Underground Economy," Journal of Development Economics 101, 167-178.

[11] Chen, B.-L. (2003), "Tax Evasion in a Model of Endogenous Growth," Review of Economic Dynamics 6, 381-403.

[12] Dabla-Norris, E., M. Gradstein, and G. Inchauste (2008), "What Causes Firms to Hide Output? the Determinants of Informality," Journal of Development Economics 85, 1-27.

[13] King, R.G. and R. Levine (1993), "Finance, Entrepreneurship and Growth," Journal of Monetary Economics 32, 513-542.

[14] Levine, R. (1997), "Financial Development and Economic Growth: Views and Agenda," Journal of Economic Literature 35, 688-726.

[15] Mason, R. and L.D. Calvin (1978), "A Study of Admitted Tax Evasion," Law and Society Review 13, 73-89.

[16] Padilla A.J. and M. Pagano (2000), "Sharing Default Information as a Borrower Discipline Device," European Economic Review 44, 1951-1980.

[17] Pagano, M. and T. Jappelli (1993), "Information Sharing in Credit Markets," Journal of Finance 48, 1693-1718.

[18] Sandmo, A. (2005), "The Theory of Tax Evasion: A Rretrospective View," National Tax Journal 58, 643-663.

[19] Schroyen, F. (1997), "Pareto Efficient Income Taxation under Costly Monitoring," Journal of Public Economics 65, 343-366. 
[20] Sheffrin, S.M. and R.K. Triest (1992), "Can Brute Force Deterrence Backfire? Perception and Attitudes in Taxpayer Compliance," in Why People Pay Taxes: Tax Compliance and Enforcement, edited by J. Slemrod, Ann Arbor: University of Michigan Press, 193-218.

[21] Slemrod, J. (2007), "Cheating Ourselves: the Economics of Tax Evasion," Journal of Economic Perspectives 21, 25-48.

[22] Slemrod, J., M. Blumenthal, and C. Christian (2001), "Taxpayer Response to an Increased Probability of Audit: Evidence from a Controlled Experiment in Minnesota." Journal of Public Economics 79, 455-83.

[23] Slemrod, J. and S. Yitzhaki (2002), "Tax Avoidance, Evasion, and Administration," Handbook of Public Economics, Volume 3, edited by Alan J. Auerbach and Martin Feldstein, Amsterdam: North Holland, 1423-1470.

[24] Spicer, M.W. and S.B. Lundstedt (1976), "Understanding Tax Evasion," Public Finance 31, 295-305.

[25] Spicer, M.W. and J.E. Thomas (1982), "Audit Probabilities and the Tax Evasion Decision: An Experimental Approach," Journal of Economic Psychology 2, 241-245.

[26] Smith, B.D. and M.J. Stutzer (1989), "Credit Rationing and Government Loan Programs: A Welfare Analysis," Real Estate Economics 17, 177-193.

[27] Stiglitz, J.E. and A. Weiss (1981), "Credit Rationing in Markets with Imperfect Information," American Economic Review 71, 393-410. 